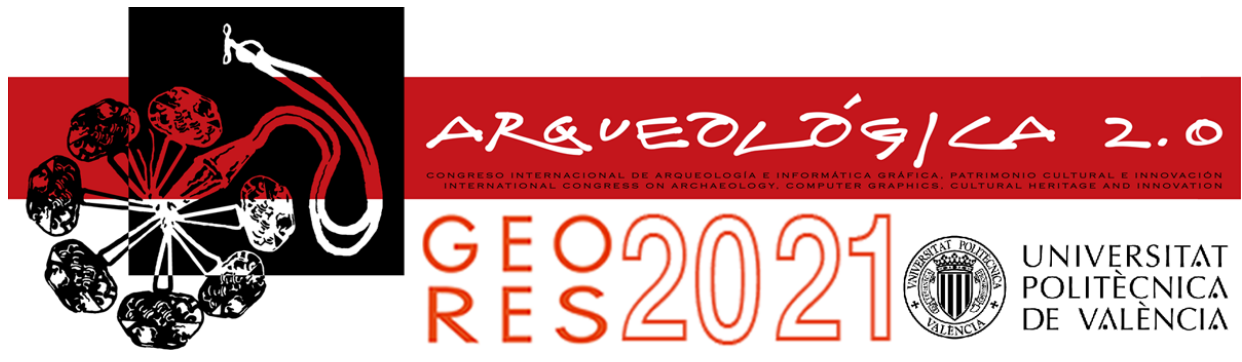

Proceedings of the joint international event $9^{\text {th }}$ ARQUEOLÓGICA

$2.0 \& 3^{\text {rd }}$ GEORES

Valencia (Spain).

26-28 April 2021

\title{
SPACE-BASED APPLICATIONS FOR BUILT CULTURAL HERITAGE: EXPERIENCE OF COPERNICUS4REGIONS PUBLICATION
}

\author{
Branka Cuca*, Raffaella Brumana \\ Department of Architecture, Built Environment and Construction Engineering, Politecnico di Milano, Piazza Leonardo da Vinci 32, 20133 \\ Milan, Italy. banka.cuca@polimi.it; raffaella.brumana@polimi.it
}

\begin{abstract}
:
NEREUS is a Network of Regions Using Space Technologies established in Brussels in 2007. The need of this network emerged out of the conviction that the regions are the key users and procurers of space-based applications, products and services. For more than a decade, the mission of the Network has been to raise awareness of the benefits that space technologies can offer to the citizens, especially in a regional context, for public services and public policies. Within this framework, and with support by the European Commission and European Space Agency, NEREUS has developed several publications that have promoted different Earth Observation applications such as "The growing uses of Copernicus across Europe's Regions" (2012) and the latest one "The Ever Growing Use of Copernicus across Europe's Regions" (2018). Politecnico di Milano was in charge of Publication management of this last use-cases collection. The paper here presented illustrates and discusses the result of the Publication with a specific focus on space-based applications and Copernicus Programme for Cultural Heritage.
\end{abstract}

Keywords: cultural heritage, earth observation, Copernicus programme, Copernicus services, space-based applications, NEREUS, ESA

\section{Importance of regional dimension to EU policies and "Copernicus4Regions" initiative}

"Copernicus4Regions" is a joint initiative of European Commission (EC), European Space Agency (ESA) and NEREUS that explores how regions in Europe have managed to tackle common challenges, shows the benefits of the Copernicus programme and invites more regions to be involved in the ecosystem of the European Earth Observation (EO) Programme called Copernicus. The Programme is composed of the space infrastructure segment and the ground segment. The space infrastructure is based on a constellation of satellites called "Sentinels" that provide a timely and systematic earth coverage for numerous applications in the domain of environmental monitoring (Copernicus, 2020).

The regional dimension in the European Union (EU) is of great importance - on an institutional level, for example, it is represented by the body called European Committee of the Regions (CoR) with a mission to represent opinions of local and regional legislations and to provide opinions and advises on new EU laws that have an impact on the life of the citizens. (Committee of the Regions - CoR, 2020). For instance, a tool called "Territorial Impact Assessments (TIAs)" is used in order to provide CoR's rapporteurs with an analysis of the potential territorial impact of different EU legislative proposals. (CoR, 2015).

As far as the Cultural Heritage and Cultural Landscape is regarded, the regional dimension has already been recognised by the Florence Landscape Convention that with Art. 5 calls for each (signatory) party "to integrate landscape into its regional and town planning policies and in its cultural, environmental, agricultural, social and economic policies, as well as in any other policies with possible direct or indirect impact on landscape" (CoE, 2000).

A more recent document on emerging issues regarding impacts and mitigation of climate change called "European Climate Pact" states that "the Climate Pact will bring together 'regions, local communities, civil society, industry and schools. Together they will design and commit to a set of pledges to bring about a change in behaviour, from the individual to the largest multinational."” (EC, 2020).

Hence, it could be argued that the regions have been recognised as one of the main actors to implement policies of interest for local management, as a direct link with the citizen and as a possible facilitator of their behavioural change.

The initiative "'CCopernicus4Regions'”' has been brought forward by NEREUS - a Network of Regions Using Space

"Corresponding Author: Branka Cuca, banka.cuca@polimi.it 
Technologies established in Brussels in 2007. The need for this network emerged out of the conviction that the regions are the key users and procurers of space-based applications, products and services. Since more than a decade, the mission of NEREUS has been to raise awareness of the benefits that space technologies can offer to the citizens.

The initiative "Copernicus4Regions", and more specifically the results of the Publication here discussed, fully recognise the importance of the regional dimension: the publication aims to highlight the best practices of space-based solutions and applications that have been put in place by regional public authorities and local players to tackle some specific challenges that affect the lives of European citizens.

The paper here presented will illustrate and discuss the result of the publication with a specific focus on spacebased applications and Copernicus Programme for Cultural Heritage.

\section{99 user stories by local and regional authorities: publication structure and discussion of results}

The publication entitled "The Ever Growing Use of Copernicus across Europe's Regions" is the result of the most recent survey on space-based applications for European regions, conducted in 2018 within "Copernicus4Regions" initiative. The selection of 99 user stories presents an insight on how public administrations across Europe are using Copernicus data and services to address their challenges and how this is positively impacting the lives of citizens.

In order to emphasise the link of EO applications and services with the specific territorial challenges, the collection procedure required for European regions (and not academies or research bodies) to be proponents of specific user stories. The selection was based on a double peer-review process, with expert reviewers selected all over European Union. The topics considered by this collection have been structured into eight (8) themes:

(i) Agriculture, Food, Forestry and Fisheries;

(ii) Biodiversity and Environmental Protection;

(iii) Climate, Water and Energy;

(iv) Territorial management and Urban Planning;

(v) Civil Protection;

(vi) Transport, Civil Infrastructure and Safety;

(vii) Public Health;

(viii) Cultural heritage, Tourism and Leisure.

The results show that almost two-thirds of the papers describe applications falling in three themes: "Agriculture, Food, Forestry and Fisheries" (32 papers), "Biodiversity and Environmental Protection" (17 papers) and "Climate, Water and Energy" (16 papers). Figure 1 illustrates the results for all topics in a pie chart.

Although the themes "Public Health" and "Cultural Heritage" have received respectively one and two publications, these results have been considered significant for two reasons: (i) EO applications in these fields have not yet reached the levels of maturity comparable to more traditional fields of applications such as agriculture or environmental monitoring and (ii) these domains were not within the original objectives of the Copernicus Programme (Copernicus, 2020). Hence, the resonance of the EO potential within the fields so apparently distant from the initial purpose of the European space programme, could already be considered a significant achievement.

\section{Track 1. Transports, Civil Infrastructure and Safety \\ \rack 2. Cultural Heritage, Tourism and Leisure \\ 园 Track 3. Biodiversity and Environmental Protection \\ Track 4. Territorial Management and Urban Planning \\ a Track 5. Public Health \\ a Track 6. Civil Protection \\ Track 7. Agriculture, Food, Forestry and Fisheries \\ Track 8. Climate, Water and Energy}

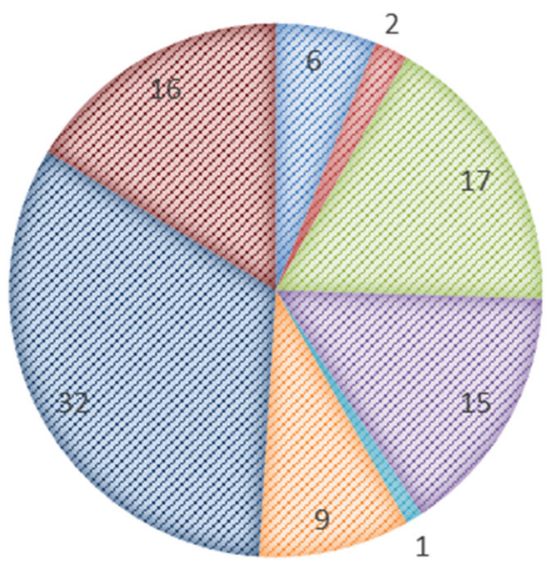

Figure 1: Distribution of the Copernicus User Stories by thematic area. Source: "Copernicus4Regions" | Second Review Panel Report.

The survey conducted has regarded four specific aspects:

(i) the challenge tackled by the application;

(ii) the space-based solution;

(iii) benefits to the citizens and

(iv) outlook to the future.

More specifically, in the space-based solution section the authors were required to refer to type of Sentinel (and/or to contributing missions) data used and to self-asses the User Maturity Level (UML) of their application. As far as the use of Sentinels are considered, use of S-2 has been recorder as highest (74 cases), which can be explained by the fact that this high-resolution optical imagery can be of effective use to LRAs in territorial management.

Regarding the UML, these have been defined by "Copernicus4Regions" initiative in following manner: UML 1- Explorer; UML 2 - Ad-hoc user; UML - 3 Pilot/ Experimental tester; UML 4 - Early Adopter and UML 5 Operational user. As a result, almost half of the publication cases identify in the definition "Pilot/Experimental tester" (UML 3, 43 use cases), while circa $15 \%$ of applications declare to be at the Operational user level (UML 5). 
It is also interesting to mention that geographical distribution of cases was highly significant: the use case have arrived from 72 different European regions and municipalities distributed across 24 Copernicus countries. Figure 2 shows a distribution of articles across countries per affiliation.

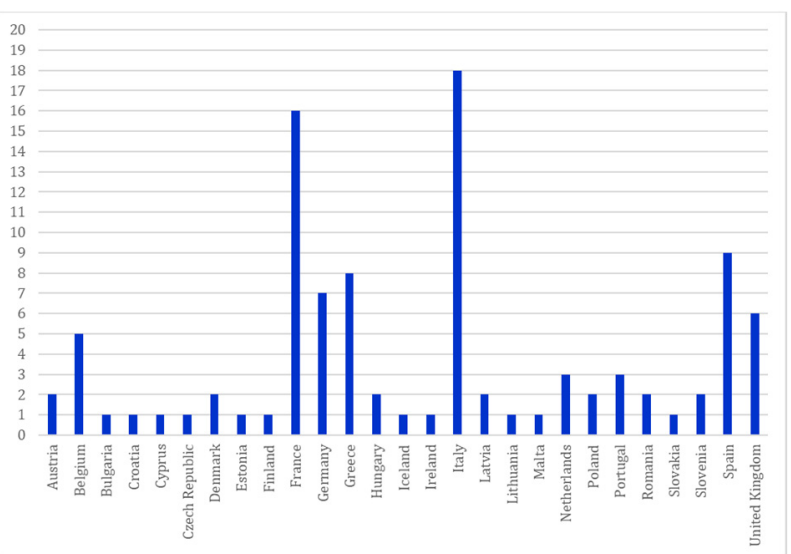

Figure 2: Distribution of articles (in numbers) across the Copernicus countries per affiliation (origin as declared by the main author). Source: "Copernicus4Regions" | Second Review Panel Report, statistics.

\section{Copernicus Services: opportunities for Cultural Heritage communities}

Scientific activities and research regarding the application of EO technologies in the domain of built Cultural Heritage has already been extensively reviewed (Lasaponara \& Masini, 2011; Giardino, 2011; Agapiou \& Lysandoru. 2015; Cuca \& Hadjimitsis 2017; Agapiou, Lysandrou, \& Hadjimitsis, 2020). However, Cultural Heritage was not a domain considered to be initially strategic for Copernicus Programme. Successively to Sentinels launch, an active response by the scientific community, but also some dramatic events involving destruction of heritage sites of world-wide importance, have put the employment of satellite-based technologies for purposes of monitoring and preservation of built heritage higher up in the political agendas. For instance, in the document "Towards an EU strategy for international cultural relations" (European Commission, 2016), EC expresses the will to share with UNESCO "satellite imagery of cultural heritage sites at risk in order to evaluate the damage and plan possible reconstruction".

Most recently in 2019, EC has released a study on "Copernicus services in support to Cultural Heritage" that has been conducted with an aim to "support the European Commission in its assessment on the possibility of initiating an institutional action for promoting the use of Copernicus data for Cultural Heritage preservation, monitoring and management" (Copernicus services in support to Cultural Heritage, 2020).

This Report, together with an broad analysis of user requirements, provides an extensive list of Copernicus capabilities in response to these needs. In particular, specific capabilities offered by the Copernicus programme are tackled by two already existing Copernicus services: (a) Copernicus Security Service and (b) Copernicus Emergency Service (CEMS). In particular: a) The EU Satellite Centre (SatCen), in charge of the Copernicus Security service in support of EU External Action (Copernicus SEA), can provide a twofold action for purposes of tangible Cultural Heritage monitoring: (i) Damage assessment: change detection products, available on-demand; (ii) Activity analysis: EO-based products analysing pre and post-human activity over Cultural Heritage sites, available on-demand and/or for monitoring activities.

b) The Joint Research Centre (JRC), on the other side, is in charge of CEMS and provides information for disaster risk and recovery as well as for emergency response related to natural disasters, extreme meteorological events and accidental man-made disasters. The Copernicus EMS targets authorised users from civil protection agencies as well as UN agencies and international NGOs and provides: (i) On-demand mapping: provision of rapid maps for emergency response, and risk and recovery maps for prevention and planning; (ii) Early warning and monitoring system: provision of geo-hazard forecast and monitoring to support situational awareness, and decision-making for prevention and preparedness purposes.

\section{Advantages and difficulties in using Sentinel imagery: a brief overview}

As described, the paper focuses on a specific experience with an attempt to highlight the results of a public survey conducted specifically among Public Authorities (PAs) at the local and regional level. That is to say that the paper refers not so much to the scientific advancement of the Copernicus programme products and services but rather to those examples that have been proposed as a concrete uptake in the practice of heritage documentation and site management.

It is, however, appropriate to mention some main advantages and possible difficulties for wider use and a better uptake of Sentinel imagery. The main advantage of Copernicus is that this space programme in general relies on a free, full and open (FFO) data policy (European Parliament, 2018). This means that data provided by the programme are open to all end-users and are available for use and possibly re-use. Hence, Sentinel data, in addition to the educational and scientific use, can be employed for developing concrete commercial solutions, hence stimulating the private sector uptake as well.

From a more technological perspective, benefits in using Sentinels regard their high temporal resolution: in case of Sentinel-1 Constellation the coverage frequency refers to 6 -days for countries of the European union and 12 days for the rest of the world, while Sentinel-2 Constellation provides a revisit time of 5 days at the equator in cloudfree conditions. In particular, Sentinel-2 swath width is $290 \mathrm{~km}$ (in comparison to Landsat 5 TM of $185 \mathrm{~km}$, and the swath width of SPOT- 5 is $120 \mathrm{~km}$ ). Sentinel-2 data are acquired with a Multi Spectral Instrument (MSI) at three spatial resolutions $(10,20$ and $60 \mathrm{~m})$, with a resolution of $10 \mathrm{~m}$ in Red, Green, Blue and NIR bands (ESA, 2020). Availability of this kind of optical multi-spectral imagery free of charge is highly stimulating also for the cultural 
heritage community that in the past has extensively relied on Landsat missions (at $30 \mathrm{~m}$ resolution in the abovementioned bands).

This paper does not specifically tackle the disadvantages of the use of Sentinel data, but some difficulties could be mentioned when dealing with satellite imagery in general. Aspects that come to mind more specifically for the "nontraditional" fields of application (such as cultural heritage domain) is a wider user-uptake of Sentinel data opportunities, often limited due to knowledge and expertise gaps. Another problem could regard the methodology frequently applied on satellite imagery in cultural heritage domain i.e. visual (and manual) investigation that could be time-consuming and potentially influenced by subjectivity of the operators. In fact, the authors of the Cases examined recognise these drawbacks and suggest some concrete solutions for the future, possibly within a larger collaboration framework of institutions and scientific disciplines (see Table 1).

Table 1: A summary of issues per section of the Publication for Case 1 and Case 2.

\begin{tabular}{|c|c|c|}
\hline Analysis per section & Case 1 & Case 2 \\
\hline Challenge tackled & $\begin{array}{l}\text { To provide PAs with a possibility to: (i) } \\
\text { monitor the condition of heritage; (ii) } \\
\text { repeat the assessment; (iii) perform timely } \\
\text { checks in case specific events of damage } \\
\text { occur. }\end{array}$ & $\begin{array}{c}\text { To analyse threats to } \mathrm{CH} \text { assets induced } \\
\text { by natural hazards or extreme } \\
\text { meteorological events as effects of } \\
\text { climate change; } \\
\text { To provide an overview of capabilities of } \\
\text { space-based solutions for monitoring geo- } \\
\text { hazards on the UNESCO WHL in Europe. }\end{array}$ \\
\hline $\begin{array}{l}\text { Space-based solution (use of Copernicus } \\
\text { data) }\end{array}$ & Sentinel-2 & Sentinel-1 \\
\hline $\begin{array}{c}\text { Usage Maturity Level (UML, as stated by } \\
\text { the authors) }\end{array}$ & $1-3$ & 3 \\
\hline Benefits to the citizens & $\begin{array}{l}\text { Assessing and monitoring of heritage at } \\
\text { risk; } \\
\text { Strengthen disaster preparedness. }\end{array}$ & $\begin{array}{c}\text { Enhancement of management practices; } \\
\text { Strengthen disaster preparedness. }\end{array}$ \\
\hline Outlook to the future & $\begin{array}{l}\text { Automation (e.g. automatic processing } \\
\text { chain); } \\
\text { Capacity building for better user uptake. }\end{array}$ & $\begin{array}{l}\text { An agreement among European } \\
\text { institutions on the use of satellite services } \\
\text { for monitoring hazards affecting } \mathrm{CH} \text {. }\end{array}$ \\
\hline
\end{tabular}

\section{Cultural Heritage use cases in "Copernicus4Regions": an overview and discussion on results}

Although the cases received on Cultural Heritage topic by the Publication were few, the paper intends to provide an illustration of these cases in order to highlight the possibilities for further advancements to the more operational phase of space-based applications in this domain.

The two use cases received on the $\mathrm{CH}$ theme will be briefly discussed here and they will be referred to as:

Case 1: an experience heritage sites at risk in the Middle East and North Africa entitled "Monitoring Heritage at Risk", presented by Italian Space Agency - ASI, (Tapete \& Cigna, 2018), the case illustrated in Figure 3.

Case 2: an experience from a project funded by a Joint Programming Imitative on Cultural Heritage and Global Change (JPI-CH) entitled "Protection of European Cultural Heritage from Geo-hazards", presented by a consortium of PROTHEGO project (Bee et al., 2018), case illustrated in Figure 4.

\subsection{The challenge}

The section of the use-cases that was dedicated to "The challenge" had as a purpose to set up a context in which a space-based application has been inserted in order to meet specific requirements of public authorities. In the two cases Authors describe two different challenges: while Case 1 focuses on risks caused by man-action, Case 2 sets the priority on monitoring of threats and damages caused by mainly natural hazards. It could be argued that, in light of Section 3 of this paper, Case 1 is closer to the topics tackled by the Copernicus Security Service while Case 2 could rely on products of Copernicus Emergency Service.

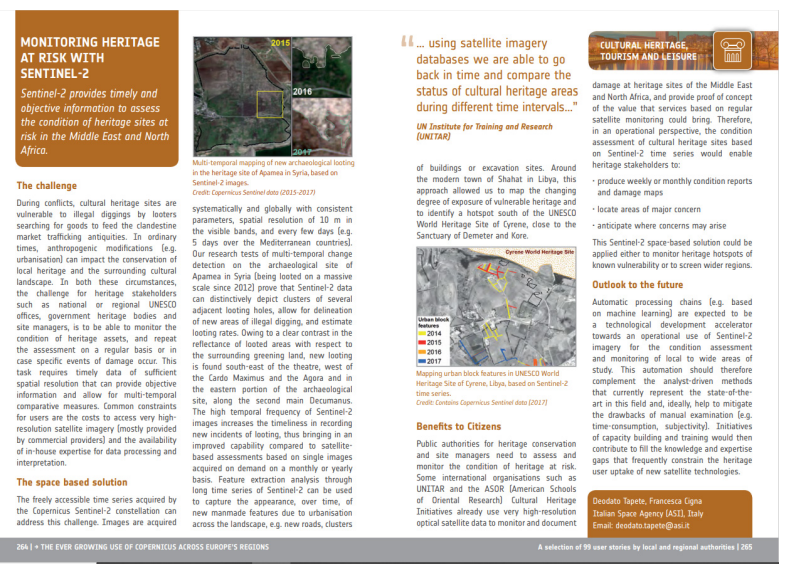

Figure 3: Case-study 1: "Monitoring Heritage at risk with Sentinel-2", pages 264-265 extracted from the publication "The Ever Growing Use of Copernicus across Europe's Regions" () NEREUS-ESA-EC. 


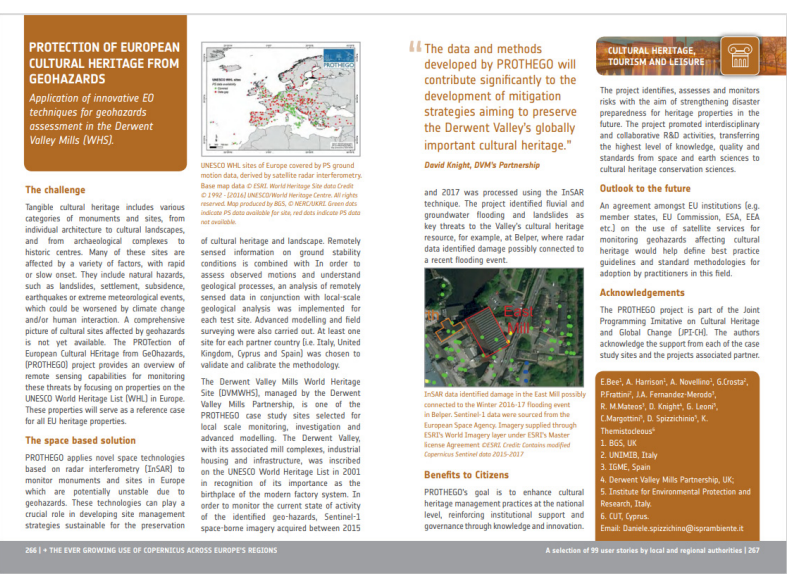

Figure 4: Case-study 2: "Protection of European Cultural Heritage from Geohazards", pages 266-267 extracted from the publication "The Ever Growing Use of Copernicus across Europe's Regions" C NEREUS-ESA-EC.

In more detail, the challenge in Case 1 has been identified as a need to provide PAs with a possibility of (i) monitoring the condition of heritage assets; (ii) repeating the assessment on a regular basis; (iii) performing timely checks in case specific events of damage occur, specifically in areas affected by armed conflicts that are under high risk of heritage looting. In particular, two specific obstacles for PA identified are "the costs to access very high resolution satellite imagery (mostly provided by commercial providers) and the availability of in-house expertise for data processing and interpretation".

Case 2 focuses on threats to Cultural Heritage assets induced by natural hazards, such as landslides, settlement, subsidence, earthquakes or extreme meteorological events caused by (or that could be worsened by) effects of climate change. The challenge of the solution was also to provide an overview of the capabilities of space-based solutions for monitoring these threats regarding the properties on the UNESCO World Heritage List (WHL) in Europe. Such first exercise should then serve as a reference case for all EU heritage properties.

\subsection{Space based solution}

Case 1 presents the work based on multi-temporal change detection on the archaeological sites in order to identify (i) single episodes of extensive looting over the past few years on a case study in Middle East (Apamea in Syria) and (ii) to map the vulnerability and exposure to other man-made threats such as unplanned urbanisation (case study in North Africa, the modern town of Shahat in Libya). The tests use systematically and globally acquired imagery with consistent parameters, the spatial resolution of $10 \mathrm{~m}$ in the visible bands, and every few days (e.g. 5 days over the Mediterranean countries). Authors state that the added value of Copernicus Programme in this case regards the high temporal frequency of Sentinel-2 images i.e. every few days. This aspect has enabled scientists to improve their observation in terms of timelines of a space-based application (specifically regarding extensive looting).

On the other side, the objective of Case 2 space-based solution was to monitor monuments and sites in Europe potentially unstable due to geo-hazards, using radar interferometry (InSAR). In this example, the processed Sentinel-1 imagery allowed the scientists to identified fluvial and groundwater flooding and landslides as a major threat to one of the use-cases (The Derwent Valley Mills World Heritage Site, UK). Such procedure has identified damage possibly connected to a contemporary flooding event (i.e. a flood in Belper, UK, 2016-2017).

The cases here identify an added value of Sentinel- 1 and Sentinel-2 for both (i) man-made damages and (ii) naturally-induced hazards. In addition, Cases illustrate how Copernicus data has been useful for damage estimation of both (i) events that happen suddenly and proceed rapidly such as earthquakes, floods or even looting episodes and (ii) those events hazardous events more consistent over time (e.g. soil erosion).

\subsection{Benefits to citizens: site managers and concerned communities}

The cases of Cultural Heritage applications are not fully operational yet as the authors identify as Usage Maturity Level (UML) 3 for both applications i.e. the level of "Pilot/ Experimental tester" for which the Local Regional Authority has already used the Copernicus-based solution in one or more trials and is concretely considering its integration within its standard practices.

At the moment of issue of the publication, both applications underline the need for an improved management of Cultural Heritage monuments and sites: as stated in Case 1: "Public authorities [...] need to assess and monitor the condition of heritage at risk", while the authors of Case 2 argue than management practices need to be enhanced by "reinforcing institutional support and governance through knowledge and innovation".

Both cases propose solutions to identify, assess and monitor threats to the heritage sites in order to strengthen disaster preparedness. In particular, from operational perspective Case 1 proposes as useful a series of concrete products such as: (i) production of weekly or monthly condition reports and damage maps; (ii) rapid location areas of major concern and (iii) simulation of possible future threats.

\section{Discussion}

Cultural Heritage and Cultural Landscapes are of importance to European regions not only for their intrinsic cultural and identity values. As largely studied in relevant European research, the investment in culture has an impact on the local economy (CHCfE, 2015). In addition, a study "World Heritage and Tourism in a Changing Climate" gave an insight on the impact of climate change effects on tourism, a specific economic sector related to built environment and traditionally linked to heritage. The report states that in the period of 1979 till 2013 a specific factor identified as one negatively affecting the outstanding universal value of the property was "Management system/management plan": In Europe and North America this number accounts for a highest number of cases i.e. $58 \%$ of investigates sites (Markham, Osipova, Lafrenz Samuels, \& Caldas, 2016). These results suggest that, in case of emergency the concrete threat could be given by the hazardous event itself; in case of ordinary administration, however, the threat 
seems to be a "hazardous attitude" towards cultural assets that could lead to inadequate maintenance and thus to a risk of an improper management of Cultural Heritage sites (as discussed in Cuca, 2017).

It is worth mentioning that in both Cases 1 and 2 of the Publication the experiences refer to UNESCO World Heritage Sites (WHS) of great importance for both scientific communities as well as humanity in general. These examples could be examined as a reference for implementation of EO technologies and space-based applications in a more systematic manner also for sites and monuments widely spread across European regions that do not yet enjoy the status of "outstanding value" but are of major importance for the culture, identity and economy of local and regional realities.

\section{Conclusions}

The paper presents a brief overview of the statistical results of the publication "The Ever Growing Use of Copernicus across Europe's Regions. A selection of 99 user stories by local and regional authorities", issued in 2018. The focus of the paper is specifically an illustration and comparison of the two space-based applications that have been received on the topic "Cultural heritage, Tourism and Leisure". Although not an initial priority of the Copernicus, the domain of Cultural Heritage and archaeology has resulted as extremely interesting, thanks to the novel capabilities offered by the programme.

The Cases here illustrated identify as significant added value the fact that Sentinel data are open and available free of charge, underlining thus the importance of the FFO data policy of the programme. Also, the Cases remind the importance of significant temporal resolution of acquired data and the possibility for frequent inspections, often of high relevance when it comes to monitoring unexpected events and damages caused by either anthropologic actions or by natural phenomena.

As Copernicus Programme is achieving its operational maturity, the future regarding its capabilities to full-fill the needs of Cultural Heritage community remain to be decided. From the cases by the "Copernicus4Regions" publication it is clear that Copernicus enabled spacebased applications are already capable of modernising the public sector and providing more efficient public services. A great technological potential of illustrated solutions (and of many more present in scientific literature) could make a substantial difference if employed systematically in practice of built Cultural Heritage monitoring, management and preservation.

\section{Acknowledgements}

This paper refers to "Copernicus4Regions" initiative that is managed by the Network of European Regions Using Space Technologies (NEREUS), under a contract from the European Space Agency and funding from the European Union, in collaboration with NEREUS. The Editorial Committee of the Publication was composed by Roya Ayazi (NEREUS), Ilaria d'Auria (NEREUS), Alessandra Tassa (European Space Agency) and Julien Turpin (European Commission). The work presented by this paper is a result of the activities conducted within a contract between NEREUS Network and Politecnico di Milano.

\section{References}

Agapiou, A., \& Lysandrou, V. (2015). Remote sensing archaeology: tracking and mapping evolution in European scientific literature from 1999 to 2015. J. Archaeol. Sci. Rep. 4, 192-200. ISSN 2352-409X. http://dx.doi.org/10.1016/j.jasrep.2015.09.010.

Agapiou, A., Lysandrou, V., \& Hadjimitsis, D. G. (2020). Earth Observation Contribution to Cultural Heritage Disaster Risk Management: Case Study of Eastern Mediterranean Open Air Archaeological Monuments and Sites. Remote Sens., $12,1330$.

CHCfE Consortium. (2015). Cultural Heritage Counts for Europe. Full report. Retrieved March 15, 2021, from http://blogs.encatc.org/culturalheritagecountsforeurope/outcomes/

Bee, E., Harrison, A., Novellino, A., Crosta, G., Frattini, P., Fernandez-Merodo, J. A., Mateos, R. M., Knight, D., Leoni, G., Margottini, C., Spizzichinio, D., \& Themistocleous, K. (2018). Protection of European Cultural Heritage from Geohazards. In NEREUS/ ESA/EC “The Ever Growing use of Copernicus across Europe's Regions", pages 266267.

Copernicus. (2020). Retrieved March 15, 2021, from https://www.copernicus.eu/en

Committee of the Regions. (2020). Retrieved March 15, 2021, from https://cor.europa.eu/en

Committee of the Regions (CoR). (2015). Renewed Territorial Impact Assessment Strategy of 2015. Retrieved March 15, 2021, from https://cor.europa.eu/en/our-work/Pages/Territorial-Impact-Assessment.aspx

Copernicus services in support to Cultural Heritage. (2020). Publications Office of the European Union, 2019. Retrieved March 15, 2021, from https://www.copernicus.eu/sites/default/files/201906/Copernicus_services_in_support_to_Cultural_heritage.pdf

Council of Europe (CoE). (2000). European Landscape Convention. Retrieved March 15, 2021, from https://www.coe.int/en/web/conventions/full-list/-/conventions/treaty/176

Cuca, B. (2017). The contribution of Earth Observation technologies to monitoring strategies of Cultural Landscapes and Sites. Int. Arch. Photogramm. Remote Sens. Spatial Inf. Sci., XLII-2NW5, 135-140. https://doi.org/10.5194/isprsarchives-XLII-2-W5-135-2017, 2017. 
Cuca, B., \& Hadjimitsis, D. G. (2017). Space technology meets policy: An overview of Earth Observation sensors for monitoring of cultural landscapes within policy framework for Cultural Heritage. Journal of Archaeological Science: Reports (JASPER), 14, 727-733, ISSN: 2352-409X. https://doi.org/10.1016/j.jasrep.2017.05.001

European Commission (EC). (2020). Joint Communication to the European Parliament and the Council "European Climate Pact”. Retrieved March 15, 2021, from https://europa.eu/climate-pact/system/files/202012/20201209\%20European\%20Climate\%20Pact\%20Communication.pdf

European Commission, (EC). (2016). Joint Communication to the European Parliament and the Council "Towards an EU strategy for international cultural relations". Retrieved March 15, 2021, from https://eur-lex.europa.eu/legalcontent/EN/TXT/?uri=JOIN\%3A2016\%3A29\%3AFIN

European Parliament (EP). (2018). Regulation on establishing the space programme of the Union and the European Union Agency for the Space Programme and repealing Regulations, COM(2018) 447 final. Retrieved March 15, 2021, from https://eur-lex.europa.eu/legal-content/EN/TXT/?uri=COM\%3A2018\%3A447\%3AFIN

ESA, Sentinel Overview. (2020). Retrieved March 15, 2021, from https://sentinel.esa.int/web/sentinel/missions

ESA, Sentinel-1. (2020). Retrieved March 15, 2021, from https://sentinel.esa.int/web/sentinel/missions/sentinel-1

ESA, Sentinel-2. (2020). Retrieved March 15, 2021, from https://sentinel.esa.int/web/sentinel/missions/sentinel-2

Giardino, M. J. (2011). A history of NASA remote sensing contributions to archaeology. J. Archaeol. Sci. 38(9), 2003-2009. September 2011. ISSN 0305-4403. http://dx.doi.org/10.1016/j.jas.2010.09.017.

Lasaponara, R., \& Masini, N. (2011). Satellite remote sensing in archaeology: past, present and future perspectives. J. Archaeol. Sci. 38(9, September 2011), 1995-2002. ISSN, 0305-4403. http://dx.doi.org/10.1016/j.jas.2011.02.002.

Markham, A., Osipova, E., Lafrenz Samuels, K., \& Caldas, A. (2016). World Heritage and Tourism in a Changing Climate. United Nations Environment Programme, Nairobi, Kenya and United Nations Educational, Scientific and Cultural Organization, Paris, France.

NEREUS, European Space Agency and European Commission. (2018). "The Ever Growing use of Copernicus across Europe's Regions: a selection of 99 user stories by local and regional authorities”, 277 pages.

Tapete D., \& Cigna F. (2018). Monitoring Heritage at risk with Sentinel-2. In NEREUS/ ESA/EC "The Ever Growing use of Copernicus across Europe's Regions", 264-265. 